\section{An Evaluation of Compliance with an Antibiotic Policy in Surgical Wards at a General Teaching Hospital in Northern Ireland}

To the Editor-Inappropriate antimicrobial use has been recognized as a contributory factor to the selection and spread of drug-resistant microorganisms, subsequently affecting the morbidity and mortality of patients who thus incur additional hospital costs. ${ }^{1}$ The main objectives of hospital antimicrobial policies are to improve patient outcomes, reduce adverse effects associated with antimicrobial use, minimize the emergence of antimicrobial resistance, and provide cost-effective treatments. ${ }^{2}$ Given the fact that antibiotic policies have been shown to decrease antimicrobial use with resulting cost savings, ${ }^{3,4}$ special attention should be devoted to ensuring full compliance with such measures. Guidance on the use of antibiotics (for empirical treatment and surgical prophylaxis) had been in place at the hospital since 1995. A user's guide to intravenous (IV) antibiotics was introduced in 1999, and all antibiotic policies were regularly reviewed and updated, with the audit taking place subsequent to an update of the policies in 2005. After this update, clinical staff were informed of the updated antibiotic policy, which was made available on the intranet via the clinical laboratory's Web page. In addition, a hard copy of the policy was placed on all wards. The aim of our study was to measure adherence to an antibiotic policy in the hospital.

Our study was carried out at Antrim Area Hospital in Northern Ireland, United Kingdom, a 426-bed general teaching hospital. The study took place in 2 surgical wards (one with 27 beds and the other with 28 beds) during the period from January 2006 through December 2006. The wards were visited daily by a microbiologist, and the patients whose infective episodes were diagnosed and who therefore received antibiotic treatment were included in our study. Details of each patient's age, sex, infectious disease diagnosis, and antibiotic treatment were recorded from their medical records and from computer systems of the microbiology department. Patients were assigned to 1 of 5 diagnostic categories on the basis of their infectious disease diagnosis: (1) gastrointestinal tract infection (GTI), (2) soft tissue infection (STI), (3) urinary tract infection (UTI), (4) lower respiratory tract infection (LRTI), and (5) other types of infection (ie, central nervous system infection, cardiovascular infection, bone infection, and joint infection). A standard questionnaire was completed by a microbiologist who answered "yes" or "no" or "not recorded" to the following 2 questions for each patient: Was the antibiotic(s) chosen in line with the antibiotic policy? Were IV antibiotics switched to oral when appropriate? The study team included a microbiologist and a research pharmacist. The study results were entered into a database (Access; Microsoft), and descriptive statistics and frequency analyses were performed using SPSS for Windows, version 14 (SPSS).

During the study period, 183 patients' medical records were investigated. Of the 183 patients, $86(47 \%)$ were male patients, and $97(53 \%)$ were female patients; the average duration of hospitalization was 11 days (range, 1-86 days). All 183 patients were assigned to 1 of 5 major diagnostic categories as follows: GTI (119 patients [65\%]), STI (14 patients [8\%]), UTI (14 patients [8\%]), LRTI (17 patients [9\%]), and other types of infection (19 patients [10\%]). For $56(31 \%)$ of the 183 patients, antimicrobial use was found to be in compliance with the hospital antibiotic policy. Adherence to the hospital antibiotic policy differed, however, depending on the diagnostic category the patient was assigned to (Table 1). For example, adherence was higher for the group of patients who were in the LRTI category (ie, 10 of 17 patients [59\%]) than for the group of patients who were in the GTI category (ie, 28 of 119 patients [24\%]). Appropriate switching from IT to oral therapy was observed for only $41(22 \%)$ of the 183 patients (Table 1 ).

TABle 1. Trends in Compliance With the Hospital Antibiotic Policy, by Diagnostic Category, January-December 2006

No. (\%) of patients, by diagnostic category and answer

\begin{tabular}{|c|c|c|c|c|c|c|c|c|c|c|c|}
\hline \multirow[b]{2}{*}{ Question } & \multicolumn{2}{|c|}{$\begin{array}{l}\text { With GTI } \\
(n=119)\end{array}$} & \multicolumn{2}{|c|}{$\begin{array}{l}\text { With STI } \\
(\mathrm{n}=14)\end{array}$} & \multicolumn{2}{|c|}{$\begin{array}{l}\text { With UTI } \\
(n=14)\end{array}$} & \multicolumn{2}{|c|}{$\begin{array}{l}\text { With LRTI } \\
(n=17)\end{array}$} & \multicolumn{2}{|c|}{$\begin{array}{l}\text { With other types } \\
\text { of infection } \\
(n=19)\end{array}$} & \multirow{2}{*}{$\begin{array}{l}\text { All patients } \\
\text { in compliance } \\
(n=183)\end{array}$} \\
\hline & Yes & No & Yes & No & Yes & No & Yes & No & Yes & No & \\
\hline $\begin{array}{l}\text { Were the antibiotic(s) chosen in } \\
\text { line with the antibiotic policy? }\end{array}$ & $28(24)$ & $64(54)$ & $5(36)$ & $7(50)$ & $5(36)$ & $6(43)$ & $10(59)$ & $2(12)$ & $8(42)$ & $8(42)$ & $56(31)$ \\
\hline $\begin{array}{l}\text { Were IV antibiotics switched to } \\
\text { oral when appropriate? }\end{array}$ & $28(24)$ & $11(9)$ & $6(43)$ & $0(0)$ & $2(14)$ & $0(0)$ & $4(24)$ & $1(6)$ & $1(5)$ & $0(0)$ & $41(22)$ \\
\hline
\end{tabular}

NoTE. Some patients were not included because of insufficient information. GTI, gastrointestinal tract infection; IV, intravenous; LRTI, lower respiratory tract infection; STI, soft tissue infection; UTI, urinary tract infection. 
Although antimicrobial resistance is a worldwide concern, it is a local problem in the first instance because selection for, and spread of, resistant microorganisms is occurring in individual hospitals and communities. ${ }^{2}$ Thus, hospital antibiotic stewardship has been developed for the prevention and containment of antimicrobial resistance, together with rigorous infection control programs. Despite the consensus on the importance of antibiotic policies in curbing inappropriate antibiotic use, the rate of compliance with the recommendations of these guidelines has been shown to be low, ranging from $18 \%$ to $33 \%$ of hospitals in compliance. ${ }^{2,3,5,6}$ The present results confirm these findings-only $31 \%$ of the prescribed antibiotics were chosen according to the hospital antibiotic policy. The findings of our study show that the number of patients who were switched from IV to oral therapy, according to the hospital antibiotic policy recommendations, was low (ie, 41 of 183 patients [22\%]). The importance of complying to this policy of switching from IV to oral therapy is 3 -fold. First, oral therapy is more convenient for the patient and for hospital staff. Second, it reduces the occurrence of vasculitisassociated peripheral vascular canulae. Third, the costs associated with oral treatment are much reduced compared with IV therapy. An appropriate switch from IV to oral therapy has been shown to be associated with a reduction in drug costs, length of hospital stay, and patient-related morbidity. ${ }^{7-9}$

In conclusion, the findings of our study indicate that restrictive interventions may have a greater impact than do persuasive interventions, confirming findings published elsewhere. ${ }^{4}$ Our study showed that, despite repeated publications on the topic, there is a lot of room for improvement in antibiotic use as a means of attacking the growing problem of antimicrobial resistance.

\section{ACKNOWLEDGMENTS}

We thank the clinical staff in the 2 surgical wards in our study for their contribution.

Potential conflicts of interest. All authors report no conflicts of interest relevant to this article.

Mamoon A. Aldeyab, PhD;

Salah M. Elshibly, MD, PhD; James C. McElnay, PhD; Elizabeth Davies, MB BCh BAO, FRCPath; Michael G. Scott, PhD; Fidelma A. Magee, BSc; Paul Leyden, MB, BCh, FFARCS(I); Mary P. Kearney, MB BCh BAO, FRCPath

From the Clinical and Practice Research Group, School of Pharmacy, Queen's University Belfast, Belfast (M.A.A., J.C.E.), and Antrim Area Hospital, Northern Trust, Antrim (S.M.E., E.D., M.G.S., F.A.M., P.L., M.P.K.), Northern Ireland.

Address reprint requests to Mary P. Kearney, MB BCh BAO, FRCPath, Antrim Area Hospital, Northern Trust, 45 Bush Road, Antrim BT42 2RL, Northern Ireland (paddy.kearney@northerntrust.hscni.net).

Infect Control Hosp Epidemiol 2009; 30:921-922

(C) 2009 by The Society for Healthcare Epidemiology of America. All rights reserved. 0899-823X/2009/3009-0020\$15.00. DOI: $10.1086 / 599308$

\section{REFERENCES}

1. Paterson DL. The role of antimicrobial management programs in optimizing antibiotic prescribing within hospitals. Clin Infect Dis 2006; 42(Suppl 2):S90-S95.

2. MacDougall C, Polk RE. Antimicrobial stewardship programs in health care systems. Clin Microbiol Rev 2005; 18:638-56.

3. Lesprit $\mathrm{P}$, Brun-Buisson C. Hospital antibiotic stewardship. Curr Opin Infect Dis 2008; 21:344-349.

4. Davey P, Brown E, Fenelon L, et al. Interventions to improve antibiotic prescribing practices for hospital inpatients. Cochrane Database Syst Rev 2005; 4:CD003543.

5. van de Beek D, de Gans J, Spanjaard L, Vermeulen M, Dankert J. Antibiotic guidelines and antibiotic use in adult bacterial meningitis in the Netherlands. J Antimicrob Chemother 2002; 49:661-666.

6. Bamberger DM, Dahl SL. Impact of voluntary vs enforced compliance of third-generation cephalosporin use in a teaching hospital. Arch Intern Med 1992; 152:554-557.

7. Sevinç F, Prins JM, Koopmans RP, et al. Early switch from intravenous to oral antibiotics: guidelines and implementation in a large teaching hospital. I Antimicrob Chemother 1999; 43:601-606.

8. von Gunten V, Amos V, Sidler AL, Beney J, Troillet N, Reymond JP. Hospital pharmacists' reinforcement of guidelines for switching from parenteral to oral antibiotics: a pilot study. Pharm World Sci 2003; 25:52-55.

9. Al-Eidan FA, McElnay JC, Scott MG, Kearney MP, Troughton KE, Jenkins $J$. Sequential antimicrobial therapy: treatment of severe lower respiratory tract infections in children. J Antimicrob Chemother 1999; 44:709-715.

\section{Outbreak of Chemical Meningitis Following Spinal Anesthesia Caused by Chemically Related Bupivacaine}

To the Editor-Meningitis following spinal anesthesia is a rare clinical complication, of bacterial etiology in the majority of cases. ${ }^{1}$ Rarer still is meningitis following spinal anesthesia from a chemical origin. Relatively common until the first half of the 20th century, chemical meningitis has scarcely been reported in the past 50 years, nearly always characterized by occurrence in isolated cases. ${ }^{2}$ The use of improved techniques for production of anesthetics is the main factor for the large reduction in incidence of this type of meningitis. ${ }^{2}$ Of the few reported cases in recent years, none was noteworthy for the relationship between chemical meningitis and chemically related anesthetics.

On February 22, 2006, a 34-year-old woman was admitted to the intensive care unit of a private hospital located in the Brazilian Amazon with signs of headache, vomiting, agitation, disorientation, and nuchal rigidity, which began 2 hours after she underwent a caesarian section delivery (case 1). A cerebrospinal fluid examination was conducted, and antibiotic therapy with vancomycin and ceftriaxone was initiated in conjunction with dexametosone. The cerebrospinal fluid analysis suggested bacterial meningitis (Table). Treatment was continued, and the patient improved rapidly.

Approximately 48 hours after the first case, a 24 -year-old woman began experiencing facial pruritis, disorientation, and 